\title{
Linking Migration and Population Studies
}

\author{
Proceedings \\ Centenary Scientific Symposium
}

\author{
Institute of Avian Research \\ "Vogelwarte Helgoland" \\ Wilhelmshaven, Germany \\ 9-10 April 2010
}

\section{Edited by}

Franz Bairlein and Peter H. Becker

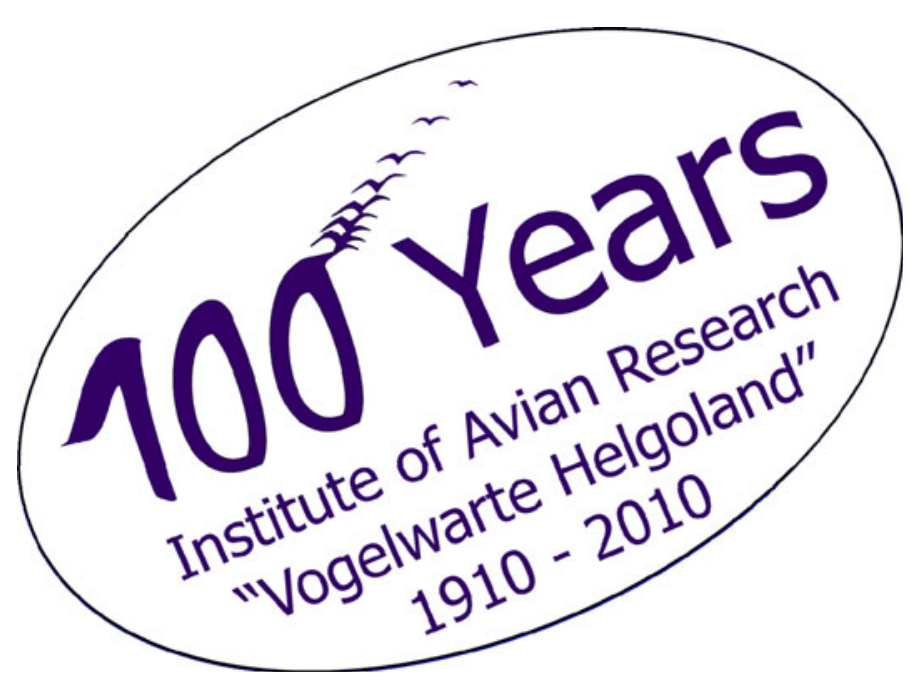

This supplement was funded by the Institute of Avian Research "Vogelwarte Helgoland", Wilhelmshaven, Germany. 